\title{
Extraction of Anemia-inducing Substance from the Human Placenta and Its Chemical Nature
}

\author{
Kiyota Oh-Uti, Kazuo Shindo, Toshiro Mikami \\ and Takeo Tanimura \\ Department of Surgery (Prof. K. Oh-Uti), \\ Faculty of Medicine, Hirosaki University, Hirosaki
}

\begin{abstract}
A number of fractions were obtained from aqueous extracts of the human placenta. These fractions were tested for anemia-inducing activity, and their chemical and physical properties were examined.

The results are summarized as follows:

1) An anemia-inducing substance $(\mathrm{P}-62)$ was extracted from the human placenta with $60 \%(\mathrm{v} / \mathrm{v})$ ethanol and was precipitated at full saturation with ammonium sulfate.

2) Intravenous injection of $\mathrm{P}-62$ produced anemia in rabbits even in a small dose of $0.02 \mathrm{mg}$ per $\mathrm{kg}$ of body weight.

3) The substance was almost homogeneous in the electrophoretic pattern.

4) Chemical analysis showed that P-62 was a mucoprotein.
\end{abstract}

It was found by Kozawa et al. ${ }^{1}$ that intravenous injection of gastric juice from patients with gastric cancer produced anemia in rabbits. The phenomenon was termed KIK reaction by them. The nature of the factor responsible for this reaction was partly elucidated by Masamune and Kawasaki, ${ }^{2} \mathrm{Harima}^{3}$ and Ogata. ${ }^{4}$ It has been shown that the anemia-inducing substance was contained not only in gastric juice of patients with gastric cancer but also in the cancerous gastric tissue. ${ }^{5-10}$ As previously reported by $\mathrm{Oh}$-Uti and his co-workers, ${ }^{11-15}$ the human placenta was found to have immunologic characteristics similar to those of gastric cancer tissue. With a view of seeing whether the human placenta contains such an anemia-inducing factor, we have carried out the present work.

\section{Methods and Results}

\section{Preparation of placental fractions}

Human placentas were kindly supplied from Prof. Shinagawa's obstetrical clinic, and after the blood was washed out under running water, they were mechanically freed from the amnion and decidua, cut into pieces, and homogenized by a Waring blendor. 
Extraction. From 3 human placentas $845 \mathrm{~g}$ of the tissue were obtained and extracted with 1.5 volumes of distilled water containing $2-3$ drops of $5 \%$ thymol alcohol, by shaking for 2 days in a cold room at $2^{\circ} \mathrm{C}$. The residue was treated further twice in the same way with decreasing volumes of water. The pooled aqueous extract of $3,000 \mathrm{ml}$ was evaporated under reduced pressure to about $1 / 3$ of the original volume and dialyzed against running water through a cellophane membrane for 48 hours.

Fractionation. The dialyzed solution (inner fluid) was evaporated to about $1 / 10$ in volume $(114 \mathrm{ml})$, and then barium acetate was added to a final concentration of $3.5 \%$. The precipitate (crude $\mathrm{P}-8$ ) was separated by centrifugation, dissolved in $100 \mathrm{ml}$ of water, and crystalline $\mathrm{Na}_{2} \mathrm{SO}_{4}$, just sufficient to carry down all the barium ion, was added. The whitish precipitate of $\mathrm{BaSO}_{4}$ was discarded after centrifugation. The supernatant was dialyzed for 3 days, evaporated to a syrup and 10 volumes of absolute ethanol were added. The resulting solution was placed in a refrigerator for several hours. The precipitate $(\mathrm{P}-8)$ was washed in ethanol and dried in a desiccator.

To the supernatant obtained after $\mathrm{Ba}(\mathrm{AcO})_{2}$ addition, ice-cooled $99 \%$ ethanol was added drop by drop until the solution contained $20 \%$ ethanol by volume. The solution was again placed in a refrigerator for several hours.

The resulting precipitate (Cr. $\mathrm{P}-20$ ) was washed with $20 \%$ ethanol several times, and then further purified in the same manner as described for $\mathrm{Cr}$. P-8. The precipitate obtained $(\mathrm{P}-20)$ was stored in a desiccator. When the supernatant and the $20 \%$ ethanol-washing of Cr. P-20 were combined, they yielded a volume of 219 ml altogether. The mixture was then chilled. After that $99 \%$ ethanol was added until the solution was of $40 \%(\mathrm{v} / \mathrm{v})$ alcohol concentration. After cooling, the precipitate produced (Cr. P-40) was removed, and ethanol was further added to the supernatant to make the concentration of ethanol $60 \%(\mathrm{v} / \mathrm{v})$, and the resulting solution was again cooled and the precipitate (Cr. P-60) was removed. These two precipitates (Cr. P-40 and Cr. P-60) were dissolved in water, $\mathrm{Na}_{2} \mathrm{SO}_{4}$ was added, and purified by the same procedure as described for Cr. P-8. The supernatant containing $60 \%$ ethanol was evaporated to about $100 \mathrm{ml}$, and crystalline $\mathrm{Na}_{2} \mathrm{SO}_{4}$, just sufficient to carry down all the barium ion, was added. Again the purification process of $\mathrm{Cr} . \mathrm{P}-8$ was repeated and the resulting precipitate (P-61) was dried and stored in a desiccator. P-61 $(410 \mathrm{mg})$ was dissolved in $100 \mathrm{ml}$ of distilled water and then saturated fully with ammonium sulfate. The mixture was allowed to stand at room temperature for 3 hours and then centrifuged. The precipitate (Cr. P-62) was washed twice with a saturated solution of $\left(\mathrm{NH}_{4}\right)_{2} \mathrm{SO}_{4}$, and added with a small amount of distilled water and dialyzed against distilled water, while the supernatant and washings of Cr. P-62, were combined together and submitted also to dialysis. After completion of dialysis, the two dialyzed fractions were each condensed under reduced pressure to syrup to which alcohol was added and the mixture was dried to powder. The powder from the precipitate by $\left(\mathrm{NH}_{4}\right)_{2^{-}}$ 


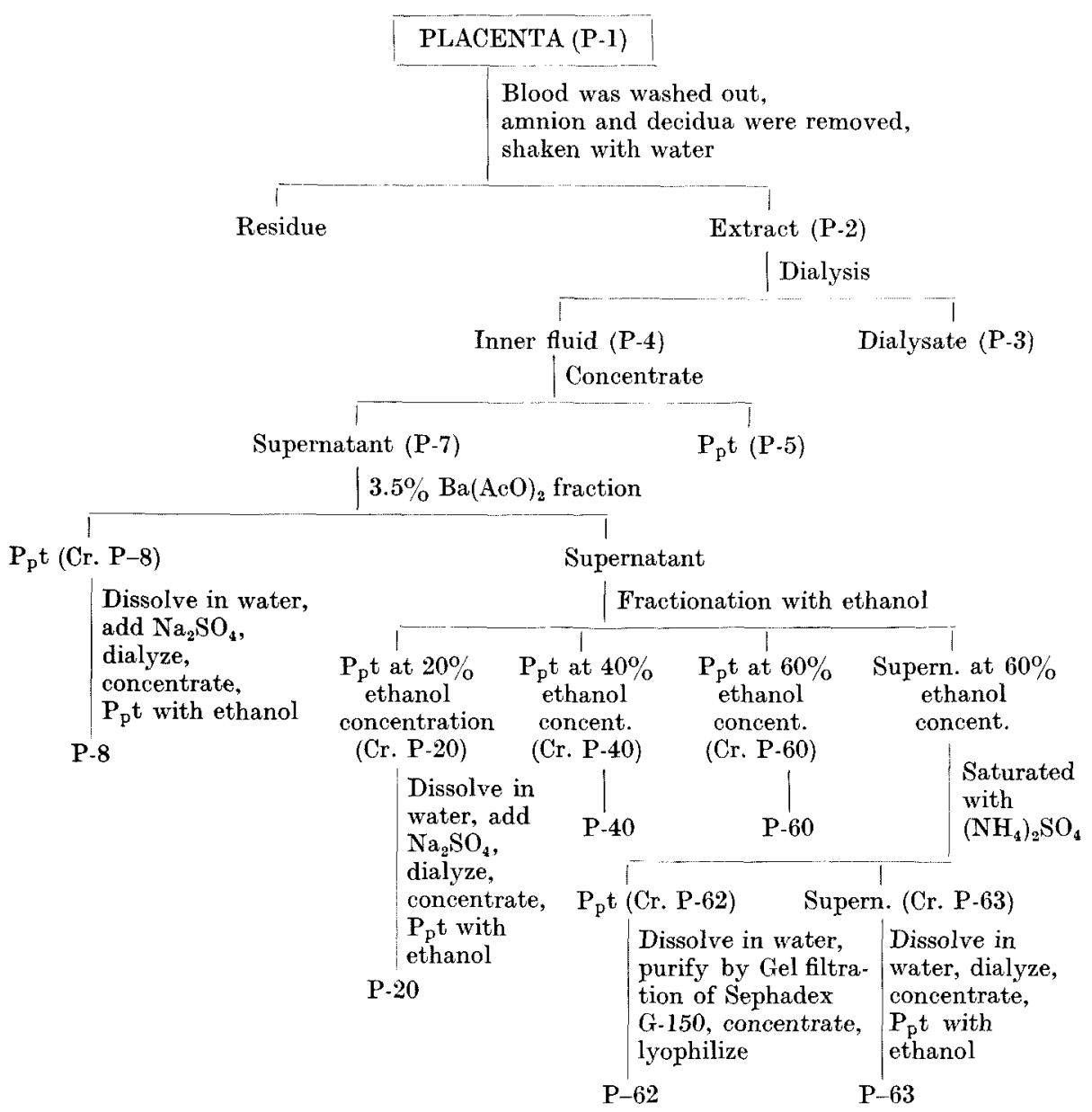

Fig. 1. Scheme of the fractionation procedures of anemia-inducing substance from human placenta.

$\mathrm{SO}_{4}$-saturation, $\mathrm{Cr} . \mathrm{P}-62$, amounted to $185 \mathrm{mg}$ and the powder from the supernatant by $\left(\mathrm{NH}_{4}\right)_{2} \mathrm{SO}_{4}$-saturation, $\mathrm{P}-63$, to $89 \mathrm{mg}$. The procedure of preparation is shown in Fig. 1.

Purification. The powder of Cr. P-62 was further purified by Gel-filtration on a column of Sephadex G-150 according to Millin's method. ${ }^{16}$ Sephadex G-150 was exhaustively washed with water and filled in a column of $45 \times 2 \mathrm{~cm}$ without salt or organic solvent. Cr. P-62 was dissolved in water to $4 \%$, placed on a column and developed with water. Fractions of $5 \mathrm{ml}$ were received with a fraction collector. From each tube of the collector, $0.3 \mathrm{ml}$ was taken and examined with FolinCiocalteu's, Anthrone and Nessler's reagents.

As illustrated in Fig. 2, a single peak of sugar containing protein was found between the 10th and 40th tubes of the elution. These fractions were combined, 


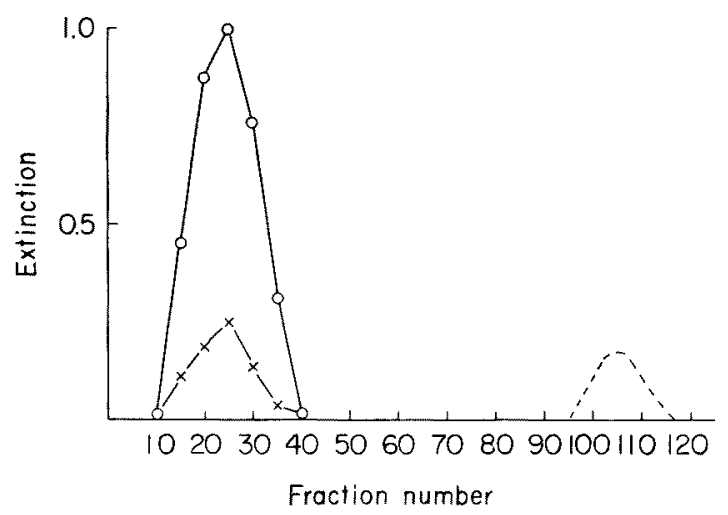

Fig. 2. Gel filtration diagram of Cr. P-62 on a column $(45 \times 2 \mathrm{~cm})$ of Sephadex G-150. Five $\mathrm{ml}$ of the fraction were collected at a flow rate of about $20 \mathrm{ml} / \mathrm{hr}$. Aliquots of $0.1 \mathrm{ml}$ each were analyzed for the Folin-Ciocalteu reaction (-०—०-), Nessler reaction (- - - $)$ and the Anthrone reagent $(-x-x-)$.

concentrated, and then lyophilized. Grayish whitish powder obtained in this way was termed P-62 and regarded as purified anemia-inducing substance.

\section{Anemia-inducing activity}

The anemia-inducing activity of the placental preparation was assayed ${ }^{17}$ in principle according to Iwatsuru and Kato's ${ }^{18}$ method. Various amounts of placental fractions were dissolved in physiological saline and injected into the auricular vein of rabbits weighing $2-3 \mathrm{~kg}$. The erythrocytes of venous blood were counted before and $1,2,3,4$ and 5 hours after the injection to determine the minimum dose per $\mathrm{kg}$ of body weight, necessary to cause a $10 \%$ decrease of erythrocytes.

P-62 fraction induced marked anemia in rabbits even in a small dose of 0.02 mg per $\mathrm{kg}$ of body weight. These results are shown in Tables 1 and 2 .

\section{Chemical properties}

Electrophoretic examination. The anemia-inducing substance from human placentas, namely P-62, was examined using a Tiselius apparatus (HTD-1 type, Hitachi Ltd.). As shown in Fig. 3, P-62 was proved to be relatively homogeneous in the electrophoretic pattern.

Paper partition chromatography of sugar and aminosugar. ${ }^{19}$ (a) Five $\mathrm{mg}$ of the anemia-inducing substance, $\mathrm{P}-62$, were sealed in a tube with $0.5 \mathrm{ml}$ of $1 \mathrm{~N} \mathrm{H}_{2} \mathrm{SO}_{4}$ and heated at $100^{\circ} \mathrm{C}$ for 5 hours. The hydrolysate was adjusted to $\mathrm{pH} 5.0-6.0$ with saturated $\mathrm{Ba}(\mathrm{OH})_{2}$ and centrifuged. The precipitate was washed with three $2 \mathrm{ml}$ portions of water warmed to $70^{\circ} \mathrm{C}$. The supernatant and washings were united and filtered under suction, and the filtrate was evaporated in vacuo over $\mathrm{CaCl}_{2}$ to dryness. The residue was dissolved in $0.05 \mathrm{ml}$ of water, and was applied onto $12 \times 60 \mathrm{~cm}$ 
TABLE 1. Anemia-inducing effect of each placental fraction on rabbits

\begin{tabular}{|c|c|c|c|c|}
\hline \multirow{2}{*}{ Fraction } & \multirow{2}{*}{$\begin{array}{l}\text { Number of } \\
\text { examinations }\end{array}$} & \multirow{2}{*}{$\begin{array}{l}\text { Substance injected } \\
\text { (mg per kg } \\
\text { body weight) }\end{array}$} & \multicolumn{2}{|c|}{ Results } \\
\hline & & & Anemia $(+)$ & Anemia $(-)$ \\
\hline $\mathbf{P}-3$ & $\begin{array}{l}3 \\
2\end{array}$ & $\begin{array}{l}1.0 \\
3.0\end{array}$ & $\begin{array}{l}0 \\
0\end{array}$ & $\begin{array}{l}3 \\
2\end{array}$ \\
\hline $\mathrm{P}-20$ & $\begin{array}{l}3 \\
2\end{array}$ & $\begin{array}{l}1.0 \\
3.0\end{array}$ & $\begin{array}{l}0 \\
0\end{array}$ & $\begin{array}{l}3 \\
2\end{array}$ \\
\hline $\mathrm{P}-40$ & $\begin{array}{l}4 \\
3\end{array}$ & $\begin{array}{l}1.0 \\
3.0\end{array}$ & $\begin{array}{l}0 \\
0\end{array}$ & $\begin{array}{l}4 \\
3\end{array}$ \\
\hline $\mathrm{P}-60$ & $\begin{array}{l}3 \\
3\end{array}$ & $\begin{array}{l}1.0 \\
1.0\end{array}$ & $\begin{array}{l}0 \\
0\end{array}$ & $\begin{array}{l}3 \\
3\end{array}$ \\
\hline P-61 & $\begin{array}{l}1 \\
1 \\
1 \\
1\end{array}$ & $\begin{array}{l}0.4 \\
0.5 \\
1.0 \\
1.25\end{array}$ & $\begin{array}{l}1 \\
1 \\
1 \\
1\end{array}$ & $\begin{array}{l}0 \\
0 \\
0 \\
0\end{array}$ \\
\hline$P-62$ & 45 & Given in Table 2 & 37 & 8 \\
\hline $\mathrm{P}-63$ & $\begin{array}{l}3 \\
3\end{array}$ & & $\begin{array}{l}2 \\
1\end{array}$ & $\begin{array}{l}1 \\
2\end{array}$ \\
\hline
\end{tabular}

TABle 2. Anemia-inducing effect of $P-62$ on rabbits

\begin{tabular}{c|r|r|c}
\hline $\begin{array}{c}\text { P-62 } \\
\text { (mg per kg body weight) }\end{array}$ & $\begin{array}{c}\text { Number of } \\
\text { examinations }\end{array}$ & Results \\
\hline 0.01 & 6 & 3 & Anemia (-) \\
0.02 & 15 & 15 & 3 \\
0.025 & 5 & 3 & 2 \\
0.03 & 2 & 2 & 0 \\
0.04 & 1 & 5 & 1 \\
0.05 & 6 & 3 & 1 \\
0.25 & 3 & 6 & 0 \\
0.5 & 7 & 37 & 1 \\
\hline Total & 45 & & 5
\end{tabular}

pieces of Toyo Roshi filter paper No. 2. Descending paper partition chromatography was made with butanol-pyridine-water mixture (5:3:2 by volume) according to the principle of Masamune and Yoshizawa. The sample was spotted $10 \mathrm{~cm}$ apart from the upper margin and developed for 24 hours. Aniline hydrogen phthalate was used as the indicator.

As shown in Fig. 4 A, P-62 gave spots at the positions corresponding to aminosugars (galactosamine and glucosamine), galactose, glucose, mannose and xylose and/ or $\mathbf{L}$-fucose in this order from above. The spots of aminosugars were connected to each other and the lower spot had some red tint suggesting overlapping of two sugars, L-fucose and xylose. 


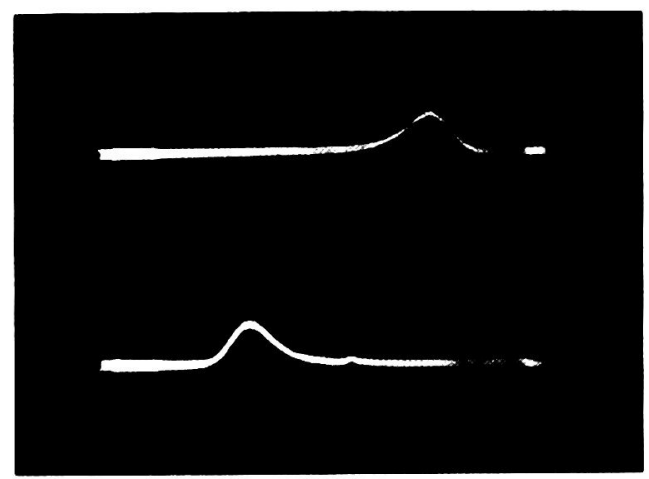

Fig. 3. Electrophoretic pattern of $1 \%$ solution of the placental anemia-inducing substance, $\mathrm{P}-62$, in $0.1 \mathrm{M}$ phosphate buffer $(\mathrm{pH} 7.8, \mu=0.2)$ after 40 and 60 minutes. Temperature $15^{\circ} \mathrm{C}$, current $6 \mathrm{~mA}$, ascending limb.

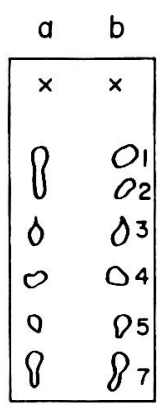

A

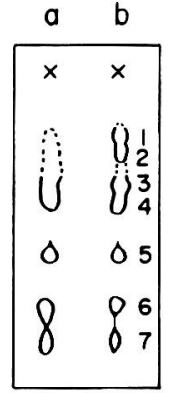

B

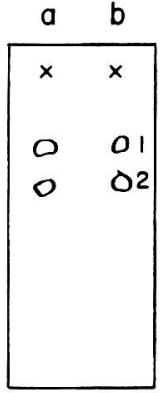

C

Fig. 4. Chromatograms of P-62.

Hydrolysis: (A) (B) $1 \mathrm{~N} \mathrm{H}_{2} \mathrm{SO}_{4}, 5$ hours, (C) $2 \mathrm{~N} \mathrm{HCl,} 14$ hours

Solvent: (A) (C) Butanol-pyridine-water (5:3:2)

(B) n-Butylacetate-acetic acid-ethanol-water $(3: 2: 1: 1)$

Chromatography in all cases was developed by descending irrigation for 24 hours at $20 \pm 1^{\circ} \mathrm{C}$. Indicator, aniline hydrogen phthalate. Reference runs were done with a $0.002 \mathrm{ml}$ portion of $1 \%$ solutions with respect to individual sugars and aminosugars. a: P-62. b: reference run. 1: galactosamine hydrochloride. 2: glucosamine hydrochloride. 3: galactose. 4: glucose. 5: mannose. 6: xylose. 7: L-fucose.

(b) Next, the hydrolysate was developed with a mixture of n-butylacetate, acetic acid, ethanol and water in a volume proportion of $3: 2: 1: 1$. The chromatograms obtained (Fig. 4 B) had weakly demonstrated spots of xylose and L-fucose.

(c) Then, $5 \mathrm{mg}$ of $\mathrm{P}-62$ was hydrolyzed with $0.5 \mathrm{ml}$ of $2 \mathrm{~N} \mathrm{HCl}$ at $100^{\circ} \mathrm{C}$ for 14 hours, and the hydrolysate was freed from most of hydrochloric acid by keeping it in a vacuum desiccator over anhydrous calcium chloride and solid caustic soda at $40^{\circ} \mathrm{C}$, with an occasional addition of a few drops of water. When $\mathrm{pH}$ of the solution reached a value of about 4 , the solution was centrifuged and the pellet 
was washed with water. The supernatant combined with the washing was evaporated to dryness. The paper chromatography was developed with the same method as described in (a).

As shown in Fig. 4C, galactosamine and glucosamine were detected.

\section{Quantitative analysis}

The results of analysis were listed in Table 3 and compared with analytical data of anemia-inducing substances from gastric juice of patients with gastric cancer (KIK factor II) and from cancerous gastric tissue (MPRI).

Table 3. Analysis of P-62 and of other anemia-inducing substances

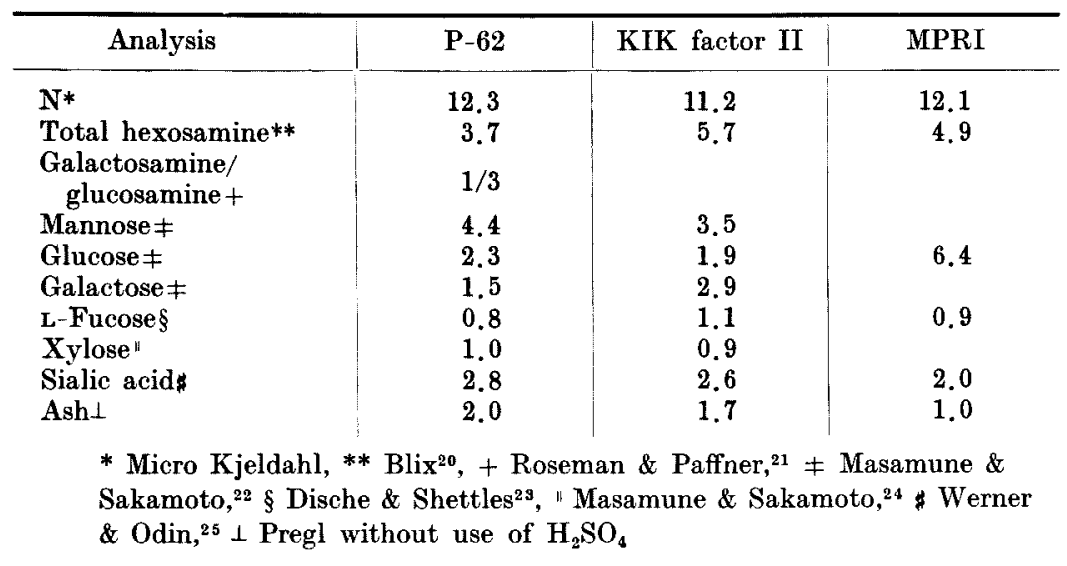

\section{Discussion}

Masamune and Kawasaki, ${ }^{2} \mathrm{Harima}^{3}$ and Ogata ${ }^{4}$ fractionated gastric juice from patients with gastric cancer in order to detect fractions with anemia-inducing activity (KIK reaction), and obtained two active substances which were each electrophoretically almost hemogeneous. On the basis of their analytical examination, they concluded that one of the substances (KIK factor I) was a mucopolysaccharide and the other (KIK factor II) a mucoprotein. In recent studies ${ }^{5-10}$ it was found that another anemia-inducing substance was contained in the cancerous gastric tissue (MPR-I), and it belonged to mucoprotein.

As previously reported by Oh-Uti et al., ${ }^{11}$ Ogawa, ${ }^{12}$ Kobayashi and his coworkers, ${ }^{13-15}$ the immunological behavior of the human placenta is clearly related to that of gastric cancer tissue. Therefore, we have carried out the present work to see whether the human placenta itself contains such an anemia-inducing substance.

A number of fractions were obtained from the aqueous extracts of the placenta by fractionation with barium acetate, ethanol and ammonium salfate in turn. Of these several fractions only the supernatant at $60 \%(\mathrm{v} / \mathrm{v})$ ethanol concentration was obviously effective. The precipitate at full saturation with ammonium 
sulfate of this fraction was further purified by gel-filtration with Sephadex G-150. The fraction obtained induced a marked anemia in rabbits even in a small dose of $0.02 \mathrm{mg}$ per $\mathrm{kg}$ of body weight and was designated as P-62.

The electrophoretic examination revealed that $\mathrm{P}-62$ was relatively homogeneous. Chemical analysis of $\mathrm{P}-62$ indicated that it belonged to mucoprotein, and that the composition of $\mathrm{P}-62$ was quantitatively very similar to that of the anemia-inducing substance from gastric juice of patients with gastric cancer (KIK factor II) ${ }^{2}$ and from cancerous gastric tissue (MPRI). ${ }^{6,8}$

\section{References}

1) Kozawa, S., Iwatsuru, R., Kawaguchi, M. \& Katagami, M. Über die Veränderung des Blutbildes bei Kaninchen durch intravenöse Injektion des Magensaftes von Magenkrebs-Kranken. Folia haemat., 1937, 57, 251-262.

2) Masamune, H. \& Kawasaki, H. Biochemical studies on carbohydrates. I. KIK factors in cancerous gastric juice. Tohoku $J$. exp. Med., 1956, 62, 369-382.

3) Harima, H. Studies on the nature of the KIK reaction. Tohoku Igaku Zassi (Jap.), $1954,50,581-588$.

4) Ogata, O. Investigation on the essential factors in the KIK reaction. Tohoku Igaku Zassi (Jap.), 1955, 52, 545-554.

5) Oh-Uti, K. Polysaccharides and a glycidamin in the tissue of gastric cancer. Tohoku J. exp. Med., 1949, 51, 297-304.

6) Oh-Uti, K., Suzuki, K. \& Yamaguchi, I. Toxic substances in cancer V. Anemiainducing substances in the tissue of gastric carcinoma. Tohoku J.exp. Med., 1958, 67, $115-121$.

7) Masamune, H., Kawasaki, H. \& Shinohara, H. Anemia-inducing substances from stomach cancer tissue. I. On a dialyzable active substance. Tohoku J.exp. Med., $1960,70,344-355$.

8) Masamune, H., Kawasaki, H., Shinohara, H., Abe, S. \& Ito, E. Anemia-inducing substances from stomach cancer tissue II. A KIK factor in stomach cancer tissue. Tohoku J. exp. Med., 1960, 72, 356-365.

9) Suzuki, K. Investigation into anemiogenic substance in the tissue of gastric carcinoma. I. Study on the extract with $10 \%$ saline. Tohoku Igaku Zassi (Jap.), 1958, $58,163-173$.

10) Suzuki, K., Oh-Uti, K., Konno, H., Koma, E., Abe, H., Yamaguchi, I., Inoue, K., Yamaguchi, M. \& Suzuki, T. Investigation into anemiogenic substances in the tissue of gastric carcinoma. III. Study on the aqueous extract. Tohoku Igaku Zassi (Jap.), 1958, 58, 180-189.

11) Oh-Uti, K., Ogawa, M., Yabuki, S. \& Kawasaki, H. On the placental substance giving the skin reaction of cancer and pregnancy. Tohoku $J$. exp. Med., 1952, 56, $177-183$.

12) Ogawa, M. On the placental substance giving the skin reaction of cancer and pregnancy II. Tohoku J. exp. Med., 1952, 56, 185-197.

13) Kobayashi, K. Studies on the specific antigens of human gastric cancer I. Tohoku J. exp. Med., 1956, 63, 185-189.

14) Kobayashi, K. Studies on the specific antigens of human gastric cancer II. Tohoku J. exp. Med., 1956, 63, 191-202.

15) Kobayashi, K. \& Kawasaki, H. Studies on the specific antigens of human gastric cancer III. Tohoku J. exp. Med., 1956, 63, 203-220.

16) Millin, D.J. \& Smith, M.H. Gel filtration and chromatography of human salivary proteins. Biochim. biophys. Acta, 1962, 62, 450-455.

17) Oh-Uti, K., Mikami, T., Shindo, K., Chida, T., Tamura, Y. \& Numata, T. Studies 
on malignant tumors and anemia. I. Investigation on the anemiogenic substance in the placental tissue. Hirosaki Igaku (Jap.), 1964, 15, 557-567.

18) Iwatsuru, R. \& Kato, I. A biological method on the diagnosis of stomach cancer. II. Gann, 1951, 42, 51-54.

19) Masamune, H. \& Yoshizawa, Z. Biochemical studies on carbohydrates. CLXI. Paper partition chromatography of sugars, in particular of hexosamines and hexuronic acids. Tohoku J. exp. Med., 1953, 59, 1-9.

20) Blix, G. The determination of hexosamines according to Elson and Morgan. Acta chim. scand., 1948, 2, 467-473.

21) Roseman, S. \& Daffner, I. Colorimetric method for determination of glucosamine and galactosamine. Anal. Chem., 1956, 28, 1743-1746.

22) Masamune, H. \& Sakamoto, M. Biochemical studies on carbohydrates. CLXXIX. Spectrophotometric determination of hexoses by the acid of thionalide. Tohoku $J$. exp. Med., 1956, 63, 345-355.

23) Dische, Z. \& Shettles, L.B. Specific color reaction of methylpentoses and a spectrophotometric micromethod for their determination. J. biol. Chem., 1948, 175, $595-603$.

24) Masamune, H. \& Sakamoto, M. Biochemical studies on carbohydrates. CLXXX. Spectrophotometric determination of pentoses in sugar mixtures and polysaccharides. Tohoku J. exp. Med., 1956, 63, 357-362.

25) Werner, I. \& Odin, L. On the pressure of sialic acid in certain glycoprotein and in gangliosides. Acta Soc. Med. Upsal., 1952, 57, 230-241. 